\title{
Turning Commercial Ceramic Membranes into a First Stage of Membranes for Post-Combustion $\mathrm{CO}_{2}$ Separation
}

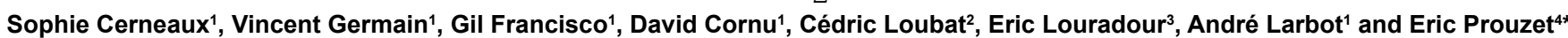

${ }^{1}$ Institut Européen des Membranes de Montpellier (IEMM) (UMR 5635), Université Montpellier II (UM2) /Centre National de la Recherche Scientifique (CNRS)/ Ecole Nationale Supérieure de Chimie de Montpellier (ENSCM), Site Halle de Technologie, 276 rue de la Galéra, F-34000 Montpellier, France

${ }^{2}$ Specific Polymers, ZAC Via Domitia, 150 Av. Des Cocardières, 34160 Castries, France

${ }^{3}$ CTI-Céramiques Techniques Industrielles, 382 Avenue du Moulinas, F-30340 Salindres, France

${ }^{4}$ University of Waterloo, Department of Chemistry, 200 University Avenue West, Waterloo N2L 3G1, Ontario, Canada

\begin{abstract}
This report describes how commercial tubular ceramic membranes, initially designed for liquid filtration, can be modified to provide the core separation components of a first stage of flue gas treatment and enrichment in post-combustion $\mathrm{CO}_{2}$ separation. Commercially available tubular NanoFiltration (NF) ceramic membranes were turned into a membrane for $\mathrm{CO}_{2}$ separation by a two-step process including additional ceramic coating and chemical grafting. The combination of ceramic coating and chemical grafting drastically modify the membrane properties and turn the membrane initially designed for liquid filtration into a membrane that displays $\mathrm{CO}_{2}$ vs $\mathrm{N}_{2}$ selectivity at the opposite of Knudsen-based selectivity, with a $\mathrm{CO}_{2}: \mathrm{N}_{2}$ ideal selectivity of 2.3. A second step of this study addressed the reduction of membrane cost, by starting with a low ultrafiltration (UF) $200 \mathrm{~nm}$ ceramic support specifically manufactured for this application in place of a NF membrane. After successful coating of a $5 \mathrm{~nm}$ and a $1 \mathrm{~nm}$ ceramic membranes, this membrane, grafted with a commercial fluorosilane molecule was tested in pure gas permeation of $\mathrm{CO}_{2}$ and $\mathrm{N}_{2}$, with an ideal selectivity $\mathrm{CO}_{2}: \mathrm{N}_{2}=3$. Finally, the same membrane, grafted with glymo, was tested against separation of a $\mathrm{CO}_{2}(20 \%): \mathrm{N}_{2}(80 \%)$ mixture, and as a function of the permeation stage-cut. $\mathrm{A} \mathrm{CO}: \mathrm{N}_{2}$ selectivity of 4 was obtained for a stage-cut of 0.5 , and even higher $\left(\mathrm{CO}_{2}: \mathrm{N}_{2}\right.$ selectivity=14) for low stage-cuts usually used for testing dense polymer membranes. These results demonstrate that commercial ceramic porous membranes can be used as starting elements for a first stage of $\mathrm{CO}_{2}$ post-combustion gas cleaning and $\mathrm{CO}_{2}$ enrichment.
\end{abstract}

\section{Introduction}

Today, anthropogenic emission of greenhouse gases embraces $\mathrm{CO}_{2}$ emissions peaking now at 2 billion tons per year [1]. Among them, capture of post-combustion $\mathrm{CO}_{2}$ released by the combustion of fossil fuels in gas turbines or coal-fired power plants, is a major challenge because flue gas are emitted at atmospheric pressure, with rather low concentration in $\mathrm{CO}_{2}(5-25 \%)$ compared with other sources, and contain a high proportion of water $(\sim 25 \%)$ as well as acid aerosols, flying ashes and corrosive elements like $\mathrm{SO}_{2}$ and $\mathrm{NO}$ [2]. The problem is clearly defined by the scale of emissions to deal with:

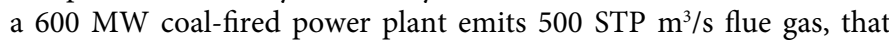
is, 460 tons $\mathrm{CO}_{2} / \mathrm{h}$ [3]. This means that among the elegant scientific responses like optimized chemical scrubbing [4], zeolites and Metal Oxide Frameworks (MOF) used as absorbent $[5,6]$, or others $[7,8]$, only technical pertinent solutions that can afford to treat such a huge amount of $\mathrm{CO}_{2}$ will be worth being farther explored. For example, among the best results reported until now for the adsorption of $\mathrm{CO}_{2}$ by MOFs (MOF-177: 1.54g CO $/ \mathrm{g} @ 4$ bar [9], MOF-200: $2.4 \mathrm{~g} \mathrm{CO}_{2} / \mathrm{g}$ @ 50 bar [10], Ni-MOF-74: 0.19g CO /g @ 1 bar [11]), and without noticing the unacceptable energy cost required for pressurizing gas at 4 bars, the amount of MOF-177 required for continuously capturing $\mathrm{CO}_{2}$ emission with a one hour adsorption/desorption cycle, would be close to 600 tons ( 300 for the adsorption stage, 300 for the desorption), which can be hardly considered. Combining the outstanding properties of MOFs for molecular selection with membranes is also on progress, but many problems have still to be solved [12]. So, as pointed recently, “... no current technologies for removing $\mathrm{CO}_{2}$ from large sources like coalbased power plants exist which satisfy the needs of safety, efficiency, and economy; further enhancement and innovation are much needed" [13].

Separation processes such as cryogenic, absorption, adsorption and membranes are usually compared in technical-economical studies, but it has been reported that membranes used to be discarded in the early stage of these evaluations, as being considered as inappropriate [14]. However, with the development of both theoretical and experimental works, the solutions provided by membranes have been highlighted, and they happen now to be promising candidates for post-combustion $\mathrm{CO}_{2}$ capture if some problems are correctly addressed and solved by involving both material science and system design engineering [2,3,14-16]. The challenges listed by these reports are the following: (i) membranes must display high selectivity toward $\mathrm{CO}_{2}$-at least 50-, (ii) it would be suitable to overcome the low $\mathrm{CO}_{2}$ concentration in the feed flow ( 12\%), (iii) the large amount of gaseous or aerosol water $(25 \%)$ present in flue gas would foul the membranes stages if not removed or drastically reduced beforehand, (iv) the low pressure of the feed gas $\left(\sim 1\right.$ bar) reduces the $\mathrm{CO}_{2}$ recovery, which is a major drawback for low permeance membranes, and (v) the raw flue gas, even after the gas cleaning and desulfurization through the FGD stage, still contain corrosive components that will destroy polymer membranes if directly exposed.

*Corresponding author: Eric Prouzet, University of Waterloo, Department of Chemistry, 200 University Avenue West, Waterloo N2L 3G1, Ontario, Canada, Tel: +1-519-888-4567; E-mail: eprouzet@uwaterloo.ca

Received October 02, 2015; Accepted November 26, 2015; Published December 03, 2015

Citation: Cerneaux S, Germain V, Francisco G, Cornu D, Loubat C, et al. (2015) Turning Commercial Ceramic Membranes into a First Stage of Membranes for PostCombustion $\mathrm{CO}_{2}$ Separation. J Membra Sci Technol 5: 139. doi:10.4172/21559589.1000139

Copyright: (C) 2015 Cerneaux S, et al. This is an open-access article distributed under the terms of the Creative Commons Attribution License, which permits unrestricted use, distribution, and reproduction in any medium, provided the original author and source are credited. 
It seems therefore that a double stage membrane system, designed according to the "enricher" double stage membrane concept [17], with a first one made of high permeance and resistant membranes, devoted to clean the raw flue gas and concentrate $\mathrm{CO}_{2}$ in the permeate side - the feed side of the second stage -, and a second one with high selectivity but fragile membranes, is a solution worth being studied, as far as all components can be produced and implemented for treating very large gaseous volumes. We report in the present study how commercial ceramic membranes can be modified by well-known procedures to achieve the requirements of this first treatment stage. As these membranes can be chemically modified to become hydrophobic, the solution offered in the present study can solve also the need for water removal, which will be demonstrated in another report.

Ceramic membranes, with pore size ranging from 2 to $50 \mathrm{~nm}$, have proven to be promising in liquid separation technology but not really in gas separation. NanoFiltration (NF) membranes with pore sizes smaller or equal to $2 \mathrm{~nm}$, having molecular weight cut-offs (MWCO) ranging from 200 to 1000 Dalton $(\mathrm{Da})$ can be the good starting elements as their pore is small enough to allow surface interaction $[18,19]$. Indeed, separation mechanisms with NF membranes generally involve both size and Donnan exclusion effects in contrast to UF membranes, giving high salts rejection rates in liquid separation [2022]. For example, Larbot et al. successfully prepared $\gamma$-alumina NF membranes using a sol-gel approach, with a MWCO of $375 \mathrm{Da}$ (pore size of $1 \mathrm{~nm}$ ), corresponding to $95 \%$ rejection of polyethylene glycol (375 Da) solutions. These NF membranes were successfully tested for mineral salts separation using Donnan exclusion $[23,24]$.

Compared with polymer membranes that offer high selectivity but rather low permeability and poor chemical durability [25], developing PIMs (Porous Inorganic Membrane) for gas separation, especially $\mathrm{CO}_{2}$ recovery, was pursued by research groups and companies, for many years now, to use their surface property to enhance molecular sieving. Indeed, when considering flue gas treatment, porous ceramic membranes offer the suitable chemical and temperature resistance, but their porosity, which enhances permeability, is a drawback for selectivity, if it is too large, or if surface defects exist. Decreasing the membrane pore size appears as a key factor to enhance selectivity without altering the gas flux and permeance, and initial reports demonstrated that silica microporous membranes with pore size of 1 $\mathrm{nm}$ could provide successful gas separation [26]. Since then, the domain of PIMs has evolved and includes now different types of materials like silica, zeolites and MOFs [25]. Surprisingly, non-siliceous metal oxides are not broadly studied.

Since the actual recovery of $\mathrm{CO}_{2}$ will require very large membrane surface area, which can only be obtained by extrapolating from current industrial manufacturing, we attached our research to explore how current commercial non-siliceous PIMs could be adapted. More specifically, we studied how the suitable porosity could be achieved by starting from commercial PIMs, and how surface modification could improve gas selectivity to hit the requirements for a first membrane stage of post-combustion $\mathrm{CO}_{2}$ capture (high permeance, selectivity in the 5-10 range, chemical durability). This study was based on preliminary works that demonstrated that surface modification induced by fluorosilane grafting could improve $\mathrm{CO}_{2}$ separation [27].

The present work reports the combination of PIM improvement by adding first a low ultrafiltration (UF) or nanofiltration (NF) membrane layer onto the internal surface of commercially ceramic supports, with the suitable chemical grafting to provide a hydrophobic surface property in order to enhance $\mathrm{CO}_{2}$ permeance. The hydrophobic treatment was obtained using the fluorinated molecule since $\mathrm{CO}_{2}$ was reported to have a higher affinity than $\mathrm{N}_{2}$ [10-13] with fluorinated molecules, which is by far beyond the single Knudsen mechanism [28], frequently observed with PIMs.

A first part of this work was devoted to explore step-by-step the influence of each component on the membrane structure and property. Therefore, we developed a zirconia membrane (Membrane $\mathrm{n}^{\circ} 1$ ) onto commercial $5 \mathrm{~nm}$ low UF alumina tubular membrane, by following the sol-gel route without plasticizer using $\mathrm{Zr}(\mathrm{OPr})_{4}$. This membrane was fully characterized, and the surface of this zirconia membrane was chemically modified in a second step with perfluorophosphonic acid $\mathrm{C}_{6} \mathrm{~F}_{13} \mathrm{C}_{2} \mathrm{H}_{4} \mathrm{PO}(\mathrm{OH})_{2}$. Its performance was evaluated in pure gas separation with $\mathrm{CO}_{2}$ and $\mathrm{N}_{2}$, to determine ideal the gas selectivity. We used these results as a starting point to optimize both the performances and the manufacturing cost of membranes.

As the membrane used in this first part, is rather expensive, with the need for coating several ceramic layers up to the $5 \mathrm{~nm}$ alumina film, a second part of this work explored if similar performances could be obtained by starting from a $200 \mathrm{~nm}$ ceramic support directly prepared by a single step extrusion process (Membrane $n^{\circ} 2$ ). These supports were directly coated with a $5 \mathrm{~nm}$ layer, then a $1 \mathrm{~nm}$ one, followed by chemical grafting with either a commercial fluorosilane, or glymo. Ideal selectivity of the membrane grafted with the hydrophobic fluorosilane was in the same range as for membrane $n^{\circ} 1$. As for the membrane grafted with glymo, it was tested against gas mixture $\left(\mathrm{CO}_{2}: 20 \%\right.$; $\mathrm{N}_{2}: 80 \%$ ), as a function of the membrane stage-cut. An exceptional $\mathrm{CO}_{2}: \mathrm{N}_{2}$ selectivity of 14 for a porous ceramic membrane prepared from industrial components, was obtained at low stage-cut -where dense polymer membranes are usually tested-, and a selectivity of 4 was obtained for stage-cut of 0.5 , which is demonstrated to be sufficient for using these membranes in a first membrane stage of cleaning and $\mathrm{CO}_{2}$ enrichment of post-combustion $\mathrm{CO}_{2}$ separation.

\section{Experimental Section}

\section{Materials}

For the membrane $n^{\circ} 1$, ultrafiltration $\gamma$-alumina membranes with pore size of $5 \mathrm{~nm}$ (T1-70) were purchased from Pall-Exekia, France. $\mathrm{Zr}$ (IV) tetraisopropoxide at 70 weight percent (wt.\%) in propanol was purchased from Fluka and $\mathrm{HNO}_{3}$ (70wt.\%) from SDS. For the membrane $\mathrm{n}^{\circ} 2$, the $5 \mathrm{~nm}$ alumina layer was made by peptisation of a Plural SB sol (Sasol, Germany). The second coating of the $1 \mathrm{~nm}$ alumina layer was made with boehmite (Sasol, Germany). Ethanol, polyethylene glycols (PEGs) with molecular weights of 400, 600, 1000, 1500, 2000 and 3000 Dalton (Da) were purchased from Sigma. $(3,3,4,4,5,5,6,6,7,7,8,8,8)$-tridecafluorooctyl perfluorophosphonic acid $\left(\mathrm{C}_{6} \mathrm{~F}_{13} \mathrm{C}_{2} \mathrm{H}_{4} \mathrm{PO}(\mathrm{OH})_{2}\right)$ denoted CFP hereafter was synthesized by Specific Polymers. (3-glycidoxypropyl)-trimethoxysilane -glymo- was purchased from Sigma-Aldrich. All the chemicals were used as received without any purification. DI water (Elga UHQ apparatus with $18 \mathrm{M} \Omega$ quality) was used for the solutions preparation.

\section{Synthesis}

Membrane $\mathbf{n}^{\circ}$ 1: Prior to its use, the commercial $5 \mathrm{~nm} \gamma$-alumina membrane was thoroughly rinsed with $18 \mathrm{M} \Omega$ water and ethanol successively, and stored in an oven at $120^{\circ} \mathrm{C}$ for 1 hour. The $\mathrm{ZrO}$ polymeric sol was prepared at room temperature by adding $0.7 \mathrm{~mL}$ of $\mathrm{Zr}(\mathrm{IV})$ tetraisopropoxide (in propanol) $\left(2.25 .10^{-3} \mathrm{~mol}\right)$ to $10 \mathrm{~mL}$ of a $0.45 \mathrm{M} \mathrm{HNO}_{3}$ solution. The sol was stirred for 24 hours and kept for another 48 hours at room temperature to allow the reduction by $15 \mathrm{wt}$. 
$\%$ of the sol concentration. The transparent resulting sol was then slipcasted for 5 minutes on a $\gamma$-alumina membrane. The casted support was finally air-dried at room temperature for 24 hours then flash-fired at $450^{\circ} \mathrm{C}$ for $1 \mathrm{~h}$ to give the zirconia membrane. To evidence the influence of the layer thickness, a second coating was realized following the same procedure. Unless specified in the text, all the membranes described in the here below manuscript were prepared with two coatings. Grafting a $10^{-2} \mathrm{M}$ solution of CFP in ethanol turned this hydrophilic zirconia membrane into a hydrophobic one. The membrane was maintained for 4 hours at reflux at $65^{\circ} \mathrm{C}$ in the grafting solution. After completion of the reaction, the membrane was removed from the grafting solution, rinsed with ethanol and acetone successively using an ultrasonication bath to remove the unreacted molecules and placed in an oven at $60^{\circ} \mathrm{C}$ for 2 hours then at $150^{\circ} \mathrm{C}$ for 12 hours. Durability of this grafted membrane was tested in real environment by exposing it directly for four months to flue gas from a coal-fired power plant, thanks to the kind contribution of a partner of the FP6 European Program NanoGLOWA (www.nanoglowa.com).

Membrane $\mathbf{n}^{\circ}$ 2: For the membrane $\mathrm{n}^{\circ}$ 2, a $10 \mathrm{~mm}$ single channel $0.250 \mu \mathrm{m}$ titania porous tubular support was prepared by direct extrusion according to usual industrial processes by CTI (France). The preparation of the $5 \mathrm{~nm}$ alumina layer was derived from a method previously developed in our group [23]. The ceramic sol was made by peptisation of a Plural SB solution by nitric acid and then the addition of polyvinyl alcohol (PVA) to enhance viscosity. The prepared solution was then tap-casted into the support. After the solution removal, the supports were left to dry for a day a room temperature and fired at $540^{\circ} \mathrm{C}$ for 2 hours. The second coating of the $1 \mathrm{~nm}$ layer alumina was performed on the top of the previous alumina layer. The alumina layer was made from boehmite obtained by the precipitation of an aluminum alkoxide in a water solution at $85^{\circ} \mathrm{C}$. The slurry was then tap-casted into the tube and left drying for 24 hours at room temperature. The support was then flash fired at $450^{\circ} \mathrm{C}$ for 1 hour. Membrane surface modification was made by grafting these membranes with either a octylfluorosilane (C8FSi) or (3-glycidoxypropyl)trimethoxysilane (glymo).

\section{Techniques}

X-ray Diffraction patterns were recorded with a X'pert Pro diffractometer (PanAnalytical, Netherlands) between 10-70 degrees in the $2 \theta$ range, using the $\mathrm{Cu} \mathrm{Ka}$ radiation $(\lambda=1.54 \AA)$. Attenuated Total Reflectance Infrared (ATR-IR) spectra were recorded on a FTIR Nicolet 510 instrument (Thermo Scientific). To facilitate the spectra acquisition, the measurements were realized on powder grafted or not. Surface morphology and thickness of the zirconia layer deposited onto the $\gamma$-alumina membrane were observed by SEM with a Hitachi S4800 SEM. A fraction of the membrane was broken and flushed with compressed air to remove the dust and then coated with platinum for electron conduction prior to being imaged. The porous volume $V p$ and specific surface area $S$ of $\mathrm{ZrO}_{2}$ were evaluated by $\mathrm{N}_{2}$ adsorptiondesorption (B.E.T. method) at 77K using a Micromeritics ASAP 2010 equipment. The ceramic powder was outgassed at $523 \mathrm{~K}$ for 12 hours prior to the analysis.

\section{Membrane tests}

Pure water and PEG solutions permeations were performed using a home-made tangential filtration pilot using a $15 \mathrm{~cm}$ long membrane [23]. As the driving force of the system is a pressure difference across the membrane, a nitrogen pressure ( 5 and 10 bar) was applied to the liquid circulating inside the membrane $(1 \mathrm{~L}$ of solution in the feed tank). The temperature was maintained at $20^{\circ} \mathrm{C}$ during the experiment using an external cooling system (Thermo scientific, Germany). The velocity of the circulating water in the filtration loop was set at $2.5 \mathrm{~m} . \mathrm{s}^{-1}$. The rejection rate of PEG solutions was followed by chromatography analysis of permeate aliquots collected on a 30 minutes time period. Before the measurement, the membrane was immersed in $18 \mathrm{M} \Omega$ water for a minimum of 2 hours to reach rapidly a stable flux at the beginning of the filtration experiment.

Gas permeation measurements were conducted using a typical gas permeation pilot. A $20 \mathrm{~cm}$ long tubular stainless steel housing was used to give a membrane permeation area of $3 \cdot 4 \cdot 10^{-3} \mathrm{~m}^{2}$. The module was linked to pressure gauges and gas flow systems that delivered either pure $\mathrm{CO}_{2}$ or $\mathrm{N}_{2}$, or a 20:80 $\mathrm{CO}_{2}: \mathrm{N}_{2}$ mixture. The feed pressure was maintained in the range of 1.5 to $4.5 \mathrm{bar}$, while the downstream permeate was vented to the atmosphere. The permeate flow rate of each gas was measured by volumetric displacement method using a soap bubble flow meter and the permeance $J\left(\mathrm{~m}^{3}(\mathrm{STP}) \mathrm{m}^{2} \cdot \mathrm{h}^{-1}\right.$.bar $\left.{ }^{-1}\right)$ was calculated using Equation 1:

$$
J=\frac{273.15}{T} \cdot \frac{v}{t} \cdot \frac{1}{A} \cdot \frac{1}{\left(P^{0}-P^{L}\right)}
$$

Where $\mathrm{T}(\mathrm{K})$ is the room temperature, $\mathrm{v}\left(\mathrm{m}^{3}\right)$ the volume of permeate collected over a period of time $t(h)$ through the membrane characterized by an effective area $\mathrm{A}\left(\mathrm{m}^{2}\right) . \mathrm{P}^{0}$ and $\mathrm{P}^{\mathrm{L}}$ (bar) correspond to the upstream and downstream pressures, respectively, and the term $\mathrm{P}^{0}-\mathrm{P}^{\mathrm{L}}$ to the corresponding pressure differential. The feed and permeate gases were analyzed using gas chromatography analysis (Varian, MicroGC 4800) directly connected to the pilot. The permeation data were recorded thirty minutes after that the feed composition was similar to the canister one.

The stage cut is defined as the permeate gas flow over retentate gas flow [29]. For the tests with pure $\mathrm{CO}_{2}$ and $\mathrm{N}_{2}$, the retentate line was closed and permeate was kept opened, which corresponds to a stagecut of 1 . The gas permeance was measured every 0.5 bar between 1.5 and 4.5 bar. All data presented are the average of five measurements in the same conditions. The $\mathrm{CO}_{2} / \mathrm{N}_{2}$ permeance ratio was calculated to evaluate the permselectivity of the zirconia membrane and thus the ideal separation factor. For tests with a gas mixture, the stage-cut was set at values lower than 1 by adjusting the outlet valve of the retentate side.

\section{Results and Discussion}

\section{Validation of membrane $n^{\circ} 1$}

Characterization of the additional zirconia coating: The nature of the zirconia crystalline phase present in the zirconia layer, was checked by following the same procedure for the sol. preparation, as the one used for the support coating, with the powder being collected and fired it at $450^{\circ} \mathrm{C}$. The analyses of the material after flash sintering, confirm that a well-crystallized tetragonal zirconia is obtained even after a very short calcination time. The resulting fine powder was grinded and analyzed by X-Ray Diffraction (XRD) (Figure 1). The XRD pattern of the as-synthesized powder (dashed line) displays only broad peaks. After calcination, diffraction peaks appeared at 30.11, 34.59, 35.14, $50.29,59.46,60.08$ and 62.84 degrees for the lattice family plans (101), (002), (110), (112), (103), (211), (202), respectively. This is in good agreement with the reported peak positions for tetragonal zirconia $[30,31]$. Sherrer analysis of the (101) diffraction peak broadening gives an average crystal size of $15 \mathrm{~nm}$. It is worth noting that even the (202) family plan, with a reported relative intensity of $5 \%$ is clearly visible in Figure 1, demonstrating therefore the high crystallinity of the obtained 
Citation: Cerneaux S, Germain V, Francisco G, Cornu D, Loubat C, et al. (2015) Turning Commercial Ceramic Membranes into a First Stage of Membranes for Post-Combustion $\mathrm{CO}_{2}$ Separation. J Membra Sci Technol 5: 139. doi:10.4172/2155-9589.1000139

Page 4 of 8

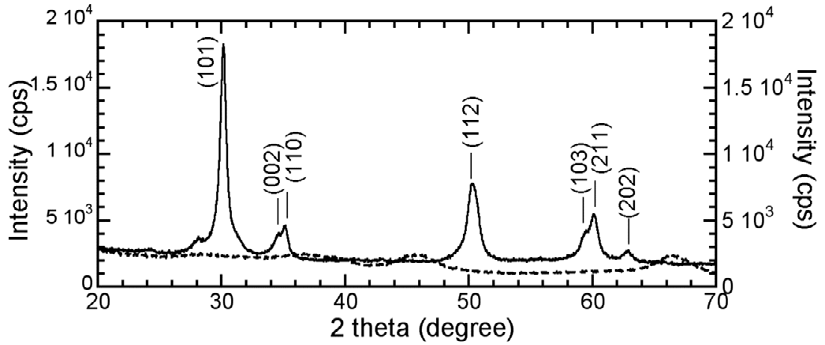

Figure 1: X-ray diffraction pattern of the zirconia powder flash-fired at $450^{\circ} \mathrm{C}$ for $1 \mathrm{~h}$.
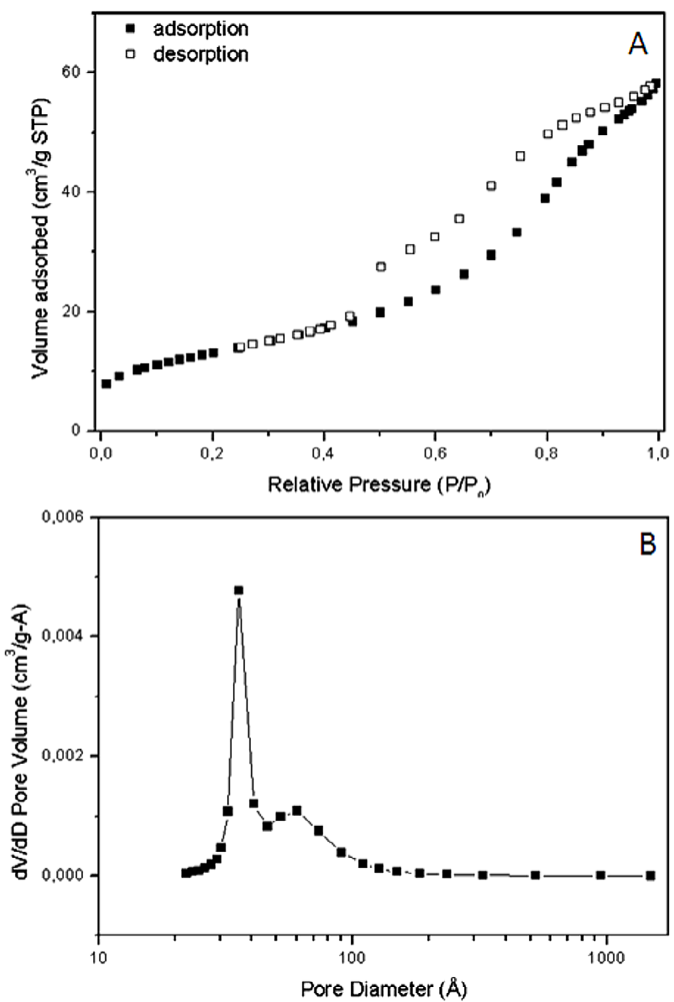

Figure 2: A) $\mathrm{N}_{2}$ adsorption-desorption isotherm at $77 \mathrm{~K}$ of the calcined zirconia powder used for membrane preparation. B) BJH pore size distribution calculated from the desorption curve.

zirconia sintered for only $1 \mathrm{~h}$ at rather low temperature.

We characterized also the porous structure of this $\mathrm{ZrO}_{2}$ powder after thermal treatment by $\mathrm{N}_{2}$ adsorption-desorption (Figure 2). Both the porous volume $\left(\mathrm{Vp}=0.09 \mathrm{~cm}^{3} \cdot \mathrm{g}^{-1}\right)$ and the BET specific surface ( $\mathrm{ss}=47$ $\left.\mathrm{m}^{2} \cdot \mathrm{g}^{-1}\right)$ are small, compared to alumina or zirconia coatings previously prepared following a similar procedure $[23,32]$. We demonstrate in the following how this limited porous volume enhances performances in gas permeation. The $\mathrm{N}_{2}$ isotherm (Figure $2 \mathrm{~A}$ ) is assigned to a Type IV curve, with a well-defined textural porosity between particles as a result of their small size (no adsorption at high partial pressure is observed). Figure 2B displays the pore size distribution (PSD) calculated by the $\mathrm{BJH}$ method. The PSD is defined within the $3-10 \mathrm{~nm}$ range, with a sharp peak at $3.5 \mathrm{~nm}$, probably better explained as a result of a curve artifact resulting from the selection of data points. This zirconia powder appears rather dense compared to similar alumina or zirconia coatings prepared following a similar procedure, which explains well by the lack of organic porogens used in the current method.

We confirmed by SEM that the morphology of the zirconia coating is better compared with a thin ceramic skin instead of a membrane (Figure 3). The zirconia layer (Figure 3C and D) deposited on the alumina support (Figure $3 \mathrm{~A}$ and $\mathrm{B}$ ) shows indeed a very thin layer of $\mathrm{ZrO}_{2}$ nanoparticles above the $5 \mathrm{~nm}$ alumina top layer. The $15 \mathrm{~nm} \mathrm{ZrO}$ nanoparticles could actually not enter the $5 \mathrm{~nm}$ porous alumina top layer, and remain on the surface (Figure $3 \mathrm{C}$ ), with this ceramic porous skin being formed.

The influence of this additional $\mathrm{ZrO}_{2}$ porous skin was tested with pure water permeation and compared to the $\gamma$-alumina $5 \mathrm{~nm}$ support alone. The flux is drastically reduced with this zirconia film compared to the bare support, decreasing from $20 \mathrm{~L} / \mathrm{m}^{2} . \mathrm{h}$ for the alumina support to $8 \mathrm{~L} / \mathrm{m}^{2}$.h at 5 bars for the zirconia membrane and from 40 to 16 $\mathrm{L} / \mathrm{m}^{2} \mathrm{~h}$, respectively at 10 bars. The water permeability deduced from these values is $1.6 \mathrm{~L} / \mathrm{m}^{2}$.h.bar for the zirconia membrane against $4 \mathrm{~L} /$ $\mathrm{m}^{2}$.h.bar for the bare alumina support.

The influence of this zirconia porous skin was confirmed by measuring the Molecular Weight Cut-Off (MWCO) of the modified membrane characterized with the rejection rate of $1 \mathrm{mM}$ PEG solutions with different molecular weights. The rejection rate was measured under different nitrogen pressure without any noticeable difference in the rejection rate of the different PEG solutions. The results obtained with a 5 bar pressure as a function of the Molecular weight is displayed in Figure 4. The MWCO defined as the $90 \%$ rejection rate is set at $2.2 \mathrm{kDa}$, which is far below the $20 \mathrm{kDa}$ MWCO delivered by a $5 \mathrm{~nm}$ alumina membrane.

We conclude from this first series of test that the addition of a zirconia coating modifies drastically the performances of the commercial alumina membrane, by reducing its water permeability from $4.0 \mathrm{~L} / \mathrm{m}^{2}$.h.bar down to $1.6 \mathrm{~L} / \mathrm{m}^{2}$.h.bar, and the MWCO from 20 $\mathrm{kDa}$ to $2.2 \mathrm{kDa}$.

Characterization of the hydrophobic chemical grafting: Low UF membranes are promising candidates for large volume gas separation because of their higher permeability than dense polymer membranes, but their poor selectivity prevents them from being used as such. We confirm in this study that a true covalent grafting of perfluorophosphonic acid improves gas selectivity toward $\mathrm{CO}_{2}$ without hampering their durability.

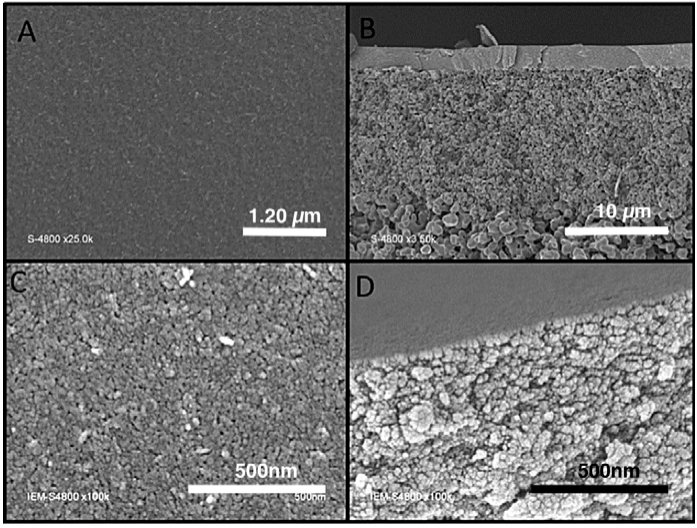

Figure 3: SEM images of of the $y$-alumina support (A: surface and $B$ : cross section) and the zirconia membrane coated onto this support (C: surface and $\mathrm{aD}$ : cross section). 
Citation: Cerneaux S, Germain V, Francisco G, Cornu D, Loubat C, et al. (2015) Turning Commercial Ceramic Membranes into a First Stage of Membranes for Post-Combustion $\mathrm{CO}_{2}$ Separation. J Membra Sci Technol 5: 139. doi:10.4172/2155-9589.1000139

Page 5 of 8

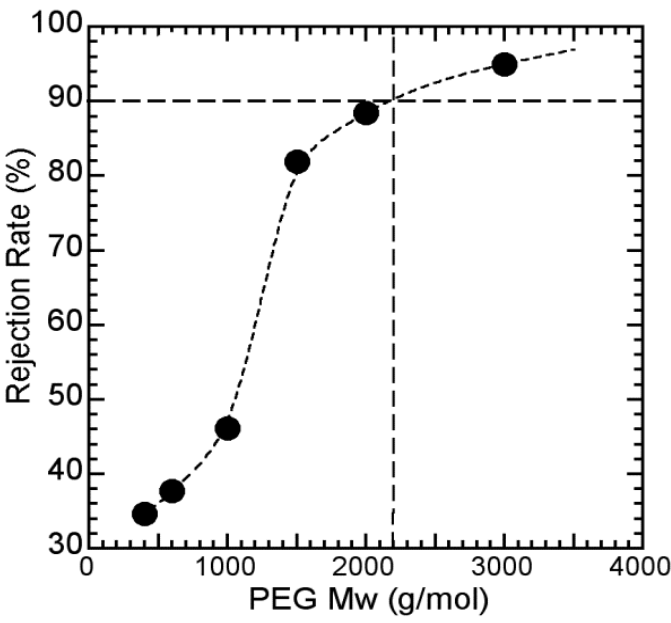

Figure 4: Rejection rate of the zirconia membrane as a function of the PEG molecular weight.
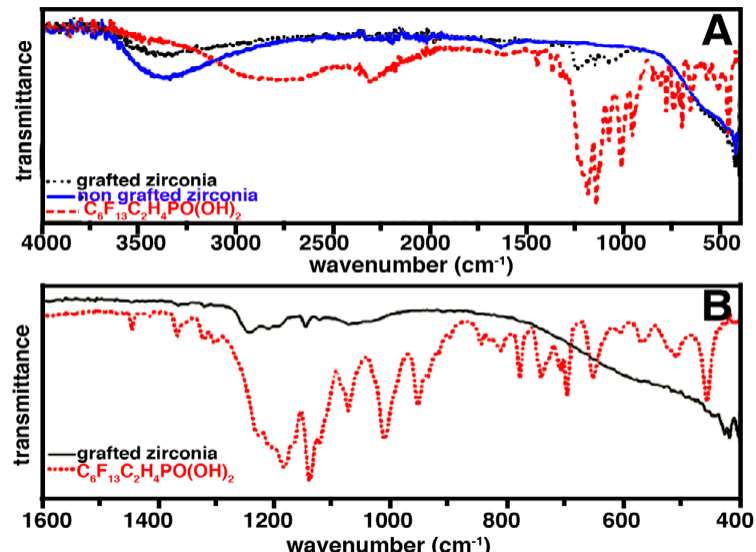

Figure 5: ATR FTIR spectra of the grafting agent (red dash), the grafted zirconia (black dots) and non grafted zirconia (blue line), A) in the 4000- 400 $\mathrm{cm}^{-1}$ range and $\mathrm{B}$ ) an enlarged section in the $1600-400 \mathrm{~cm}^{-1}$ range.

As it had been reported that the modification of the surface of a ceramic membrane by fluorinated molecule modifies the membrane gas selectivity [27], we modified the surface of the zirconia coating by grafting (3,3,4,4,5,5,6,6,7,7,8,8,8)-tridecafluorooctyl perfluorophosphonic acid (CFP) through its reaction between the acid function and the oxide surface.

The FT-IR spectra of bare and chemically modified zirconia as well as the CFP molecule are reported in Figure 5. Zirconia bare powder is characterized by a broad signal centered at around $3400 \mathrm{~cm}^{-1}$ and a small vibration band at $1650 \mathrm{~cm}^{-1}$, corresponding to hydroxyl groups or adsorbed water. The CFP FT-IR spectrum is characterized by several vibration modes in the $1,500-800 \mathrm{~cm}^{-1}$ domain. Upon surface modification resulting from the chemical reaction between the acid functionality of $\mathrm{CFP}$ and the metal oxide surface, the $\mathrm{OH}$ groups react with the phosphonic acid groups $\left(3,000-2,000 \mathrm{~cm}^{-1}\right.$ range) to give $\mathrm{Zr}$ $\mathrm{O}-\mathrm{P}$ bonds. This is evidenced by the reduction in the $\mathrm{OH}$ stretching domain $\left(3,000-2,000 \mathrm{~cm}^{-1}\right)$ disappearance of the broad signal between 2700 and $2550 \mathrm{~cm}^{-1}$ and the appearance of several vibration bands $\left(1205,1130,1070,1020 \mathrm{~cm}^{-1}\right.$ for $v \mathrm{CFx}, v \mathrm{P}-\mathrm{C}$ at $1145 \mathrm{~cm}^{-1}, v \mathrm{P}=\mathrm{O}$ around 1350-1250) at low frequency, ranging from 1,400 to $800 \mathrm{~cm}^{-1}$, characteristic of the perfluoroalkyl chains [33-35].

We tested the surface property of the grafted zirconia by measuring the water contact angle on a flat zirconia support made with the same conditions. The value obtained with a homemade apparatus, is equal to $149^{\circ}$ (Figure $6 \mathrm{~A}$ ), which ranges the hydrophobic support close to superhydrophobic materials [36]. Before going further in the study of gas separation, we validated that this membrane can be exposed for a long time ( 4 months) to actual flue gas emitted by a coal-fired power plant (Figure 6B and C) without any macroscopic degradation of structure or property. Unlike polymeric materials tested in parallel, which were destroyed within several hours, our membranes did not display any obvious deterioration, and the water angle contact, measured after this 4 month exposure, remained the same and even higher $\left(153^{\circ}\right)$ as a result of soot deposited onto. This stability is the result, not only of the high thermal and chemical resistance of ceramic membranes, but also of the CFP polymer, which is very stable up to $250^{\circ} \mathrm{C}$, as displayed in Figure 7.

Gas permeation tests and ideal selectivity: The influence of each addition to the initial $5 \mathrm{~nm}$ alumina membrane was studied against gas permeance with pure $\mathrm{CO}_{2}$ and $\mathrm{N}_{2}$. We compared the bare support, a membrane with a single zirconia layer $\left(\mathrm{ZrO}_{2} / 1 /\right)$, a membrane with two zirconia layers $\left(\mathrm{ZrO}_{2} / 2 /\right)$, and this double-coated membrane after grafting $\left(\mathrm{ZrO}_{2} / 2 /-\mathrm{CFP}\right)$. We observed a significant reduction in gas permeance with the double-coated zirconia membrane, and grafting of this double-coated membrane $\left(\mathrm{ZrO}_{2} / 2 /-\mathrm{CFP}\right)$, provided an increase in the $\mathrm{CO}_{2} / \mathrm{N}_{2}$ selectivity up to 2.5 .

For the bare support and the $\mathrm{ZrO}_{2} / 1 /$ membrane (Figure $8 \mathrm{~A}$ ), the single coating of the $\mathrm{ZrO}_{2}$ skin does not modify drastically the transmembrane gas flow, and the values of permeance, which varies linearly with the applied pressure, are in the same range $\left(\sim 45 \mathrm{~m}^{3} / \mathrm{m}^{2}\right.$.bar $)$.
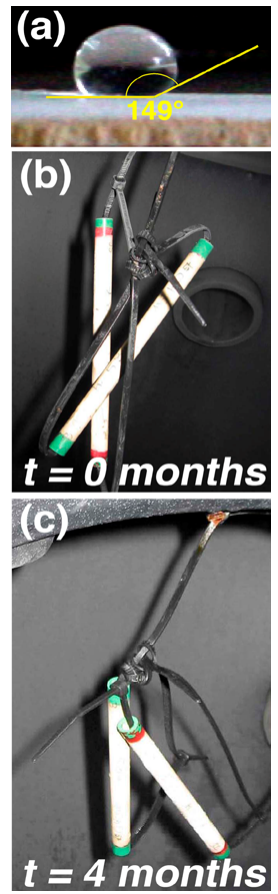

Figure 6: (a) contact angle for the superhydrophobic zirconia surface obtained after grafting; grafted tubular membranes exposed to a power plant flue gas at $(b) t=0$, and $(c) t=4$ months. 
Citation: Cerneaux S, Germain V, Francisco G, Cornu D, Loubat C, et al. (2015) Turning Commercial Ceramic Membranes into a First Stage of Membranes for Post-Combustion $\mathrm{CO}_{2}$ Separation. J Membra Sci Technol 5: 139. doi:10.4172/2155-9589.1000139

Page 6 of 8

Applying a second coating $\left(\mathrm{ZrO}_{2} / 2 /\right)$ divides by 2 the permeance (Figure 8A), but the difference in gas flow does not demonstrate a high selectivity.

Figure $8 \mathrm{~B}$ displays the results of permeance measurements made with a double-coated zirconia membrane modified by grafting $\left(\mathrm{ZrO}_{2} / 2 /\right.$-CFP). The permeance was measured for pure $\mathrm{N}_{2}$ and $\mathrm{CO}_{2}$ within a broader pressure difference range ( 0.4 to 3.5 bars) than in Figure $8 \mathrm{~A}$. The gas permeance varies linearly with the applied pressure, and it is markedly reduced from $25 \mathrm{~m}^{3} / \mathrm{m}^{2}$.bar for the initial nongrafted membrane $\left(\mathrm{ZrO}_{2} / 2 /\right)$, down to less than $0.15 \mathrm{~m}^{3} / \mathrm{m}^{2}$.bar after

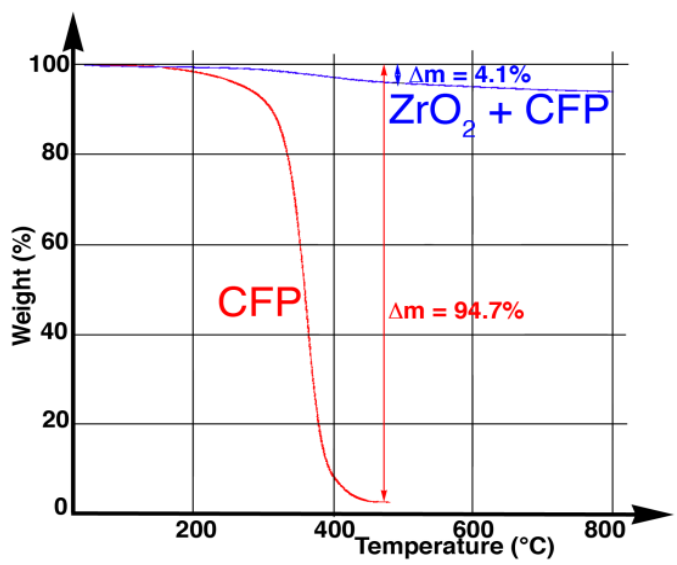

Figure 7: TGA analysis of the CFP polymer alone (red) and the $\mathrm{ZrO}_{2} / \mathrm{CFP}$ grafted ceramic.

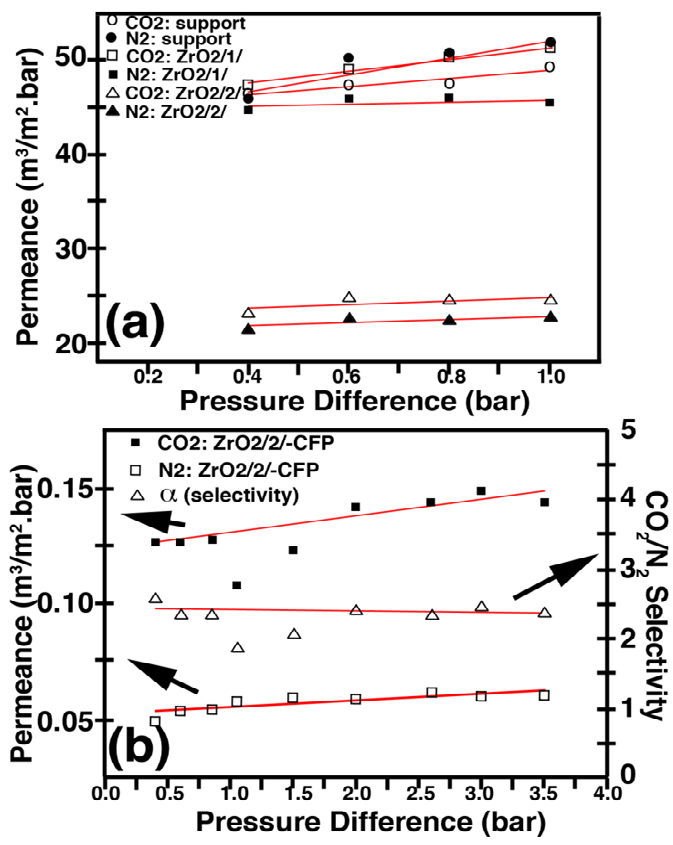

Figure 8: (a) $\mathrm{N}_{2}$ and $\mathrm{CO}_{2}$ permeance for the bare support (circle), the zirconia membrane $\mathrm{ZrO}_{2} / 1 /$ with one coating (square), and the zirconia membrane $\mathrm{ZrO}_{2} / 2 /$ with 2 coatings (triangle) as a function of the applied gas pressure; (b) $\mathrm{N}_{2}$ and $\mathrm{CO}_{2}$ permeance and selectivity of the double coated zirconia CFPmodified membrane $\left(\mathrm{ZrO}_{2} / 2 /\right.$-CFP)

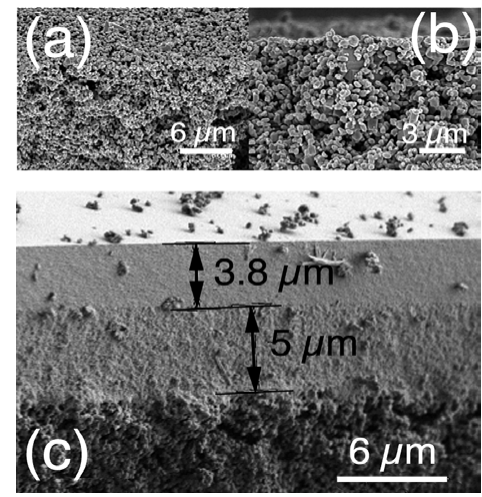

Figure 9: SEM micrographies of the surface (a) and cross section (b) of the $250 \mathrm{~nm}$ ceramic support, and (c) of the successive $5 \mathrm{~nm}$ (bottom) and $1 \mathrm{~nm}$ alumina layers coated on the previous support.

grafting $\left(\mathrm{ZrO}_{2} / 2 /-\mathrm{CFP}\right)$. The ideal selectivity calculated from the $\mathrm{CO}_{2}$ over $\mathrm{N}_{2}$ permeance (Figure $8 \mathrm{~B}$ ) is equal to 2.3 . This ideal selectivity of 2.3 obtained with a tubular commercial ceramic support modified by a well-known slip casting method and the chemical grafting of a suitable chemical, compares well with the most recent values obtained with hybrid materials like ZIF-9 metal oxide framework (MOFs) membranes prepared onto limited alumina supports, which offered an ideal selectivity of 6.9 but with a method that can hardly be extended to large membrane surface area [37], or ZIF-8 MOFs prepared on stainless steel porous tubes, which presented an opposite pure Knudsen-based $\mathrm{CO}_{2} / \mathrm{N}_{2}$ selectivity of 0.75 [38].

\section{Validation of membrane $n^{\circ} 2$}

Membrane preparation: Figure 9 displays SEM micrographies of the CTI $250 \mathrm{~nm}$ support $(\mathrm{a}, \mathrm{b})$. $\mathrm{Hg}$ porosimetry gives $47 \%$ porosity and a median pore diameter of $0.235 \mu \mathrm{m}$. Observation of the additional membranes (Figure 9C) show homogeneous defect-free layers.

This membrane was grafted with either the C8FSi molecule, or a silane bearing an epoxy function (glymo), which is known for displaying specific interaction with $\mathrm{CO}_{2}$.

Membrane properties: This membrane was tested against pure gas and the evolution of gas flow (STP conditions) for pure $\mathrm{CO}_{2}$ and $\mathrm{N}_{2}$ as a function of the pressure difference, is given in Figure 10. Permeance calculated from the slope of the linear fit for each gas, gives a value of $0.104 \mathrm{STP} \mathrm{m}^{3} / \mathrm{m}^{2}$.h and of $0.03 \mathrm{STP} \mathrm{m} / \mathrm{m}^{2}$.h for $\mathrm{CO}_{2}$ and $\mathrm{N}_{2}$, respectively, with an ideal selectivity evaluated at 3.4. This value confirms that the membrane obtained by a direct coating of a $5 \mathrm{~nm}$ and $1 \mathrm{~nm}$.

\section{Membrane testing: selectivity $v s$ stage-cut}

As defined before, the stage-cut (SC) is defined as the permeate gas flow over retentate gas flow [29]. Without this parameter, the actual evaluation of membranes performances can hardly be conducted. Indeed, the measurement of pure gas permeance, which corresponds to $\mathrm{SC}=1$, is principally an evaluation of the material affinity, and the ideal selectivity defined as the ratio of pure gas permeance corresponds to a parameter that quantifies the relative material affinity toward different gases. At the opposite, for a $\mathrm{SC}=0$, there would not be any driving force for the cross membrane flow. We show in the following that the actual membrane selectivity must be evaluated under the light of stage-cut, which defines how much of the feed gas is actually treated. 
Citation: Cerneaux S, Germain V, Francisco G, Cornu D, Loubat C, et al. (2015) Turning Commercial Ceramic Membranes into a First Stage of Membranes for Post-Combustion $\mathrm{CO}_{2}$ Separation. J Membra Sci Technol 5: 139. doi:10.4172/2155-9589.1000139

Page 7 of 8

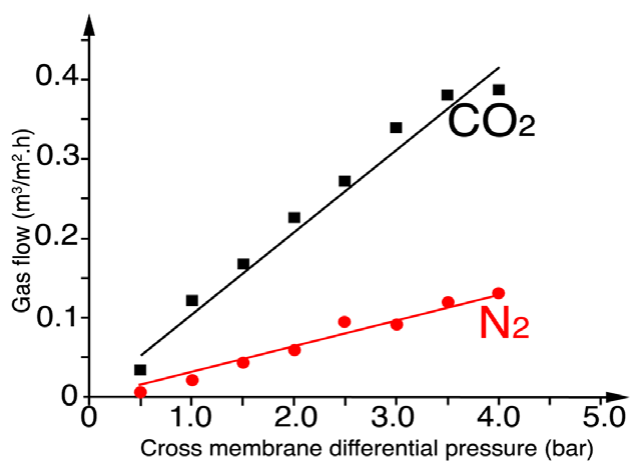

Figure 10: Flow of pure $\mathrm{CO}_{2}$ and $\mathrm{N}_{2}$ through the membrane $\mathrm{n}^{\circ} 2$ grafted with a C8 fluorosilane (C8FSi).
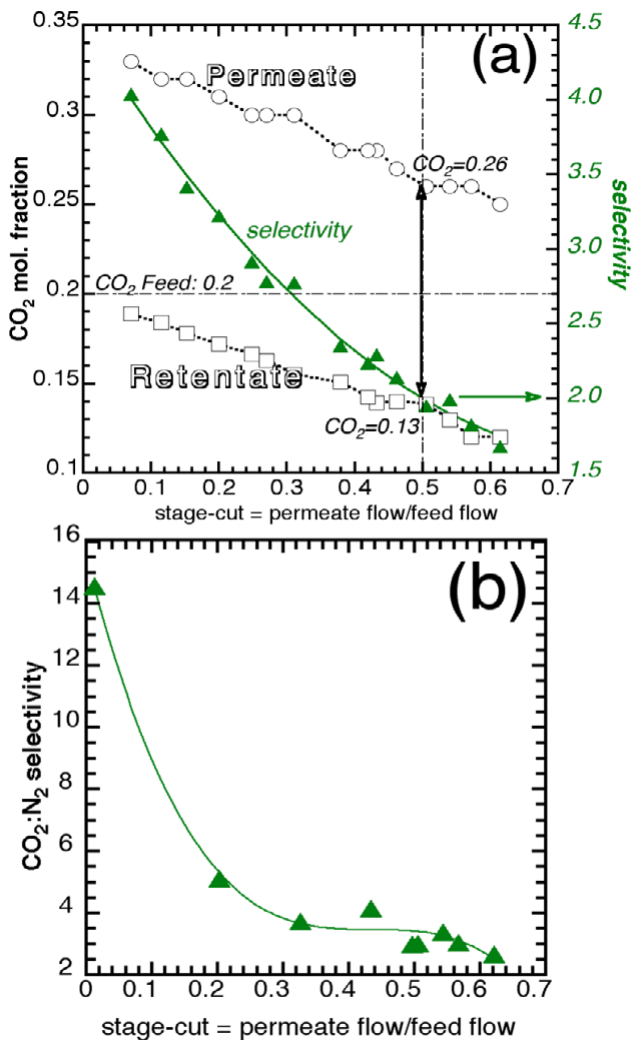

Figure 11: (a) Evolution of (i) the molar fraction of $\mathrm{CO}_{2}$ in both the permeate and retentate, and (ii) $\mathrm{CO}_{2}: \mathrm{N}_{2}$ selectivity, as a function of the stage-cut, for a $\left(20 \% \mathrm{CO}_{2}: 80 \% \mathrm{~N}_{2}\right)$ feed mixture, for the membrane $\mathrm{n}^{\circ} 2$ grafted with fluorosilane $(\mathrm{C} 8 \mathrm{FSi})$. The horizontal line corresponds to the initial concentration in $\mathrm{CO}_{2}\left(\mathrm{CO}_{2}\right.$ Feed: 0.2$) ;$ (b) Evolution of the $\mathrm{CO}_{2}: \mathrm{N}_{2}$ selectivity, as a function of the stage-cut for a $\left(20 \% \mathrm{CO}_{2}: 80 \% \mathrm{~N}_{2}\right)$ feed mixture, for the membrane $n^{\circ} 2$ grafted with glymo.

Testing the actual membrane properties requires a stage-cut lower than one, which will create a trade-off between the actual membrane selectivity, hence the gas purity, and the gas flow in the permeate, hence the global gas recovery. This is illustrated in Figure 11A with the membrane $\mathrm{n}^{\circ} 2$ grafted with $\mathrm{C} 8 \mathrm{FS}$ i where the actual $\mathrm{CO}_{2}$ molar fractions in both permeate and retentate sides, of a $\left(20 \% \mathrm{CO}_{2}: 80 \% \mathrm{~N}_{2}\right)$ feed mixture, are reported as a function of the stage-cut (SC). For a
SC of 0.5 (50\% feed flow across the membrane), the permeate gas is $30 \%$ enriched in $\mathrm{CO}_{2}(0.2$ to 0.26$)$, and the retentate is impoverished in parallel $(0.2$ to 1.3$)$

The $\mathrm{CO}_{2}: \mathrm{N}_{2}$ selectivity is also reported. This selectivity decreases from 4.0 at SC $=0.1$, where only $10 \%$ of feed flow goes across the membrane, down to 1.7 at $\mathrm{SC}=0.6$, with $60 \%$ of the feed flow going across the membrane (the line plotted in Figure $11 \mathrm{~A}$ is the result of a second degree polynomial fit of the experimental values). These results illustrate well the difference between the ideal $\mathrm{CO}_{2}: \mathrm{N}_{2}$ selectivity of the material equal to 3.4, and the actual membrane selectivity, which can be evaluated for different stage-cuts $(0.1 ; 0.3 ; 0.5 ; 0.6)$ and equal to 3.8 , $2.7,2.0$, and 1.8 , respectively.

Despite their promises for blocking the water aerosol present in the flue gas, which makes the membranes grafted with perfluoro chemical groups, good candidates for a first stage of postcombustion $\mathrm{CO}_{2}$ separation, the $\mathrm{CO}_{2}: \mathrm{N}_{2}$ selectivity remains too small to achieve the performances in gas enrichment expected for such a first separation stage. We confirmed that our method of PIM surface functionalization could work with other chemical groups. (3-glycidoxypropyl)trimethoxysilane is mostly used as a precursor for dense hybrid membranes for proton exchange in fuel cells [39], but the epoxy group was demonstrated to exhibit affinity toward $\mathrm{CO}_{2}[40,41]$. Tests with a membrane $\mathrm{n}^{\circ} 2$ grafted with (3-glycidoxypropyl)-trimethoxysilane (glymo) demonstrate a significant improvement with a $\mathrm{CO}_{2}: \mathrm{N}_{2}$ selectivity doubled for a stage-cut of 0.5 , and equal to 10 for a stagecut of 0.1 (Figure 11B). These values do not reach selectivity of 50 observed with dense hybrid membranes [41], but a selectivity of 4 for a stage-cut of 0.5 , would allow the feed gas in the second membrane stage to be $50 \%$ enriched in $\mathrm{CO}_{2}$, compared with the initial flue gas (see Figure $11 \mathrm{~A}$ ), which could significantly increase the $\mathrm{CO}_{2}$ purity and recovery in a second high selectivity membrane stage, as demonstrated by modeling studies $[2,15]$.

\section{Conclusion}

We have successfully modified commercial gamma alumina $5 \mathrm{~nm}$ membranes by applying an additional coating of tetragonal zirconia, using a sol-gel process, in order to achieve a final pore size reduction down to $3.5 \mathrm{~nm}$, compatible with gas permeation. This pore size reduction was confirmed by the drastic reduction in water flow. Surface modification of this modified membrane, with the chemical grafting of $(3,3,4,4,5,5,6,6,7,7,8,8,8)$-tridecafluorooctyl perfluorophosphonic acid, using a phosphonic acid function as grafting head, led the membrane surface to become superhydrophobic. This new surface property allowed us to achieve a significant $\mathrm{CO} 2$ over $\mathrm{N} 2$ selectivity in gas permeation, especially by tuning the membrane stage-cut, to allow a significant flow going to the permeate. These properties, along with the chemical and abrasion resistance of ceramic membranes, make them the perfect candidates for a first membrane stage dealing with gas cleaning and $\mathrm{CO}_{2}$ enrichment in the treatment of power plant raw flue gas, before sending this cleaned flue gas to a second high selectivity stage of polymer membranes.

\section{Acknowledgment}

The authors thank the European Union through the NanoGLOWA FP6 program, for financial support.

\section{References}

1. Ciferno JP, Fout TE, Jones AP, Murphy JT (2009) Capturing Carbon from Existing Coal-Fired Power Plants. Chem Eng Prog 105: 33-41.

2. Brunetti A, Scura F, Barbieri G, Drioli E (2010) Membrane technologies for CO2 separation. J Memb Sci 359: 115-125. 
Citation: Cerneaux S, Germain V, Francisco G, Cornu D, Loubat C, et al. (2015) Turning Commercial Ceramic Membranes into a First Stage of Membranes for Post-Combustion $\mathrm{CO}_{2}$ Separation. J Membra Sci Technol 5: 139. doi:10.4172/2155-9589.1000139

Page 8 of 8

3. Merkel TC, Lin H, Wei X, Baker R (2010) Power plant post-combustion carbon dioxide capture: An opportunity for membranes. J Memb Sci 359: 126-139.

4. Sharma SD, Azzi M (2014) A critical review of existing strategies for emission control in the monoethanolamine-based carbon capture process and some recommendations for improved strategies. Fuel 121: 178-188.

5. Sabouni R, Kazemian H, Rohani S (2014) Carbon dioxide capturing technologies: a review focusing on metal organic framework materials (MOFs). Environ Sci Pollut Res 21: 5427-5449.

6. Krishna R, van Baten JM (2012) A comparison of the CO2 capture characteristics of zeolites and metal-organic frameworks. Sep Purif Technol 87: 120-126.

7. D'Alessandro DM, Smit B, Long JR (2010) Carbon Dioxide Capture: Prospects for New Materials. Angew Chem-Int Edit 49: 6058-6082.

8. Choi S, Drese JH, Jones CW (2009) Adsorbent Materials for Carbon Dioxide Capture from Large Anthropogenic Point Sources. Chem Sus Chem 2: 796-854.

9. Férey G (2008) Hybrid porous solids: past, present, future. Chemical Society Review 37: 191-214.

10. Furukawa H, Yaghi OM (2009) Storage of Hydrogen, Methane, and Carbon Dioxide in Highly Porous Covalent Organic Frameworks for Clean Energy Applications. J Am Chem Soc 131: 8875-8883.

11. Bae Y-S, Snurr RQ (2011) Development and Evaluation of Porous Materials for Carbon Dioxide Separation and Capture. Angew Chem-Int Edit 50: 1158611596.

12. Shah M, McCarthy MC, Sachdeva S, Lee AK, Jeong HK (2012) Current Status of Metal-Organic Framework Membranes for Gas Separations: Promises and Challenges. I\&EC res 51: 2179-2199.

13. Li B, Duan Y, Luebke D, Morreale B (2013) Advances in $\mathrm{CO}_{2}$ capture technology: A patent review. Appl Energy 102: 1439-1447.

14. Favre $E$ (2007) Carbon dioxide recovery from post-combustion processes: Can gas permeation membranes compete with absorption? J Memb Sci 294: 50-59.

15. Brunetti A, Drioli E, Lee YM, Barbieri G (2014) Engineering evaluation of CO2 separation by membrane gas separation systems. J Memb Sci 454: 305-315.

16. Luis P, Van der Bruggen B (2013) The role of membranes in post-combustion CO2 capture. Greenhouse Gases-Science and Technology 3: 318-337.

17. Zhao L, Riensche E, Blum L (2010) Stolten D Multi-stage gas separation membrane processes used in post-combustion capture: Energetic and economic analyses. J Memb Sci 359: 160-172.

18. Sarbolouki MN (1982) A general diagram for estimating pore-size of ultrafiltration and reverse-osmosis membranes. Sep Sci Technol 17: 381-386.

19. Sharma RR, Agrawal R, Chellam S (2003) Temperature effects on sieving characteristics of thin-film composite nanofiltration membranes: pore size distributions and transport parameters. J Memb Sci 223: 69-87.

20. Bowen WR, Mukhtar H (1996) Characterisation and prediction of separation performance of nanofiltration membranes. J Memb Sci 112: 263-274.

21. Cadotte J, Forester R, Kim M, Petersen R, Stocker T (1988) Nanofiltration membranes broaden the use of membrane separation technology. Desalination 70: $77-88$

22. Rautenbach R, Groschl A (1990) Separation potential of nanofiltration membranes. Desalination 77: 73-84

23. Larbot A, Alami-Younssi S, Persin M, Sarrazin J, Cot L (1994) Preparation of a g-Alumina Nanofiltration Membrane. J Memb Sci 97: 167

24. Levenstein R, Hasson D, Semiat R (1996) Utilization of the Donnan effect for improving electrolyte separation with nanofiltration membranes. J Memb Sci 116: 77-92.

25. Pera-Titus $\mathrm{M}$ (2014) Porous Inorganic Membranes for $\mathrm{CO}_{2}$ Capture: Present and Prospects. Chem Rev 114: 1413-1492.
26. De Vos RA, Maier WF, Verweij H (1999) Hydrophobic silica membranes for gas separation. J Memb Sci 158: 277-288.

27. Abidi N, Sivade A, Bourret D, Larbot A, Boutevin B, et al. (2006) Surface modification of mesoporous membranes by fluoro-silane coupling reagent for CO2 separation. J Memb Sci 270: 101-107.

28. Villet RH, Wilhelm RH (1961) Knudsen flow-diffusion in porous pellets Industrial and Engineering Chemistry 53: 837-840.

29. Koros WJ, Ma YH, Shimidzu T (1996) Terminology for membranes and membrane processes. J Memb Sci 120: 149-159.

30. Kikkawa S, Kijima A, Hirota K, Yamamoto O (2002) Crystal structure of zirconia prepared with alumina by coprecipitation. J Am Ceram Soc 85: 721-723.

31. Srivastava A, Dongare MK (1987) Low-temperature preparation of tetragonal zirconia. Mater Lett 5: 111-115.

32. Etienne J, Larbot A, Julbe A, Guizard C, Cot L (1994) A microporous zirconia membrane prepared by the sol-gel process from zirconyl oxalate. J Memb Sc 86: 95-102.

33. Kim JD, Mori T, Honma I (2007) Anhydrous proton conductivity of a larnellastructured inorganic-organic zirconium-monododecyl phosphate crystalline hybrid. J Power Sources 172: 694-697.

34. Wang X, Ma X, Chen T, Qin X, Tang Q (2011) The homogenization of zirconium hydroxide phosphonate-supported ruthenium catalyst in asymmetric hydrogenation. Catal Commu 12: 583-588.

35. Vermeulen LA, Burgmeyer SJ (1999) Reactivity of a new zirconium phosphonate phase, $\mathrm{Zr}-2(\mathrm{O} 3 \mathrm{P}-\mathrm{CH} 2 \mathrm{CH} 2$-bipyridinium- $\mathrm{CH} 2 \mathrm{CH} 2-\mathrm{PO} 3) \mathrm{X}-6$ center dot $2 \mathrm{H}(2) \mathrm{O}$ toward organic and inorganic monophosphonates. J Solid State Chem 147 520-526.

36. Erbil HY, Demirel AL, Avci Y, Mert O (2003) Transformation of a Simple Plastic into a Superhydrophobic Surface. Science 299: 1377-1380.

37. Liu Y, Zeng G, Pan Y, Lai Z (2011) Synthesis of highly c-oriented ZIF-69 membranes by secondary growth and their gas permeation properties. J Memb Sci 379: 46-51.

38. Venna SR, Zhu MQ, Li SG, Carreon MA (2014) Knudsen diffusion through ZIF-8 membranes synthesized by secondary seeded growth. J Porous Mater 21: $235-240$.

39. Inoue, Uma T, Nogami M (2008) Performance of $\mathrm{H}-2 / \mathrm{O}-2$ fuel cell using membrane electrolyte of phosphotungstic acid-modified 3-glycidoxypropyltrimethoxysilanes. J Memb Sci 323: 148-152.

40. Sforca ML, Yoshida IVP, Nunes SP (1999) Organic-inorganic membranes prepared from polyether diamine and epoxy silane. J Memb Sci 159: 197-207.

41. Nistor C, Shishatskiy S, Popa M, Nunes SP (2009) $\mathrm{CO}_{2}$ Selective membranes based on epoxy silane. Rev Roum Chim 54: 603-610. 